\title{
Tear film MMP accumulation and corneal disease
}

\author{
V A Smith, H Rishmawi, H Hussein, D L Easty
}

\begin{abstract}
Backgroundlaims-Matrix metalloproteinases (MMPs) accumulate in the tears of patients with active peripheral ulcerative keratitis (PUK) but it is unknown whether these enzymes have a central role in disease progression. The aims of the present investigation were to determine the source of these enzymes and to ascertain whether their accumulation in tears is a phenomenon specific to PUK or a general feature of other anterior segment diseases.

Methods-The experimental samples were obtained from the culture media of conjunctival and corneal epithelial cells, from fractionated blood plasma and leucocytes of healthy subjects and patients with rheumatoid arthritis, and from the tears of healthy subjects and patients with a variety of anterior segment diseases. The MMPs of all samples were visualised by zymography and tear samples were assayed using nitrophenol acetate and an MMP-9 susceptible quenched fluorescent peptide as substrate.
\end{abstract}

Results-The major MMPs that accumulate in the tears of patients with rheumatoid arthritis with active ocular disease are MMP-9 and a species of $M_{r} 116000$. By comparing the zymographic activity profiles of the gelatinases present in the samples obtained, it was deduced that the main source of these MMPs was granulocytes. Their accumulation in tears was not unique to patients with PUK; detectable amounts of the enzymes also occurred in the tears of patients with keratoconus with associated atopic disease, patients undergoing treatment for herpetic eye disease, and patients with systemic and nonsystemic dry eye disease.

Conclusion-The MMPs that accumulate in tears are mainly derived from granulocytes. This may be effected by autoimmune diseases that involve ocular tissue or by ocular diseases that induce an inflammatory response.

University of Bristol, Division of Ophthalmology, Bristol Eye Hospital, Bristol BS1 2LX, UK V A Smith

H Rishmawi

H Hussein

D L Easty

Correspondence to:

DrV A Smith

Val.Smith@bristol.ac.uk

Accepted 1 August 2000
A well known ocular example of MMP induced pathology is peripheral ulcerative keratitis (PUK). Signs of this chronic progressive corneal disease include peripheral thinning and the formation of a perforation prone gutter. End stage perforation is effected by the interstitial collagenase MMP-1 abnormally located in the cornea of patients with PUK. ${ }^{9}$ This enzyme, together with the collagenase produced by neutrophils and classified as MMP-8, are the only mammalian enzymes known to be capable of initiating hydrolysis of fibrillar type I collagen, ${ }^{2}{ }^{10}$ the major component of the corneal stroma.

The gelatinases MMP-2 and MMP-9 are enzymes that will hydrolyse type IV collagen, the major component of basement membranes. ${ }^{1112}$ In addition to interstitial collagenase, these enzymes have been implicated in the early phase pathology of PUK. ${ }^{13}$ The suggestion that these MMPs may be involved in PUK is based on the observation that MMP-2 production is upregulated in keratocytes cultured from perforated corneas of patients with PUK, and the finding that the quantity of MMP-9 in tear samples taken from eyes of patients with rheumatoid arthritis is correlated with the extent of PUK progression in the corresponding corneas.

Because of the observed correlation between tear film MMP content and clinical evidence of PUK progression, it has been suggested that the zymographic visualisation of these enzymes in tears could be reliably used as a monitor of disease activity. However, although this is a possibility, to date there is no information pertaining to the source of these enzymes and whether their appearance in tears is specific to PUK. These questions have been addressed in the present study.

\section{Methods}

EXPERIMENTAL MATERIALS

Possible sites of synthesis of the MMPs found in the tears of patients with PUK include the conjunctiva and corneal epithelium. To determine the range of MMPs produced by these tissues, their cells were cultured. In addition, because PUK is an ocular complication of rheumatoid arthritis, the possibility that the enzymes were produced by the activated inflammatory cells that accumulate at the limbus of the corneas of patients with active PUK was also considered. To investigate this, both healthy individuals and patients with rheumatoid arthritis, with or without associated ocular disease, provided tear and blood samples for MMP analysis.

To determine whether MMP accumulation in tears was a specific feature of PUK, tear samples were obtained from normal healthy individuals and from patients with various anterior segment diseases. 
Table 1 Clinical information relating to the patients with rheumatoid arthritis who donated both tear and blood samples

\begin{tabular}{llll}
\hline Age/sex & $\begin{array}{l}\text { Duration of disease } \\
\text { (years) }\end{array}$ & Ocular complications & $\begin{array}{l}\text { Steroids } \\
\text { (local/systemic) }\end{array}$ \\
\hline $85 / \mathrm{F}$ & 18 & None & $-/-$ \\
$63 / \mathrm{M}$ & 13 & None & $-/+$ \\
$62 / \mathrm{F}$ & 40 & Keratoconjunctivitis sicca & $-/+$ \\
$70 / \mathrm{F}$ & 20 & Keratoconjunctivitis sicca & $-/-$ \\
$71 / \mathrm{F}$ & 18 & Keratoconjunctivitis sicca & $-/-$ \\
$75 / \mathrm{F}$ & 20 & Bilateral corneal melt; bilateral & $+/+$ \\
ECCE + PKP & Left corneal melt; right central & $+/-$ \\
$77 / \mathrm{F}$ & 20 & thinning; left PKP & \\
$63 / \mathrm{M}$ & Left peripheral thinning & \\
\hline
\end{tabular}

$\mathrm{ECCE}=$ extracapsular cataract extraction; $\mathrm{PKP}=$ penetrating keratoplasty.

\section{Conjunctival and corneal tissues}

Conjunctival biopsy specimens were obtained from consenting patients with perforated corneas who were undergoing graft surgery. The corneas from which epithelial cell cultures were grown were obtained from the Bristol CTS Eye Bank. They had been rejected for transplantation because of a medical contraindication and permission to use the tissue for research purposes had been obtained.

\section{Tear samples}

Tear samples of five normal subjects and eight patients with rheumatoid arthritis (with or without an associated ocular disease) were collected on Schirmer test strips. These were placed in small sterile vials and stored at $-20^{\circ} \mathrm{C}$ prior to analysis.

Tear samples from the remainder of the normal subjects and the patients with various anterior segment diseases were collected using small, fine tipped sterile pastettes and stored in Eppendorf tubes at $-20^{\circ} \mathrm{C}$. Prior to collection,

Table 2 Clinical information relating to patients with anterior ocular disease (tear donors)

\begin{tabular}{|c|c|c|c|}
\hline Patient No & Age/sex & Ocular condition & Treatment \\
\hline 1 & $31 / \mathrm{M}$ & Keratoconus (no atopy, corneal graft) & Steroid \\
\hline 2 & $21 / \mathrm{M}$ & Keratoconus (no atopy, corneal graft) & None \\
\hline 3 & $34 / \mathrm{M}$ & Keratoconus (no atopy, corneal graft) & Steroid \\
\hline 4 & $23 / \mathrm{M}$ & Keratoconus (NMR, corneal graft) & Steroid \\
\hline 5 & $36 / \mathrm{F}$ & Keratoconus (NMR) & None \\
\hline 6 & $34 / \mathrm{M}$ & Keratoconus (NMR) & Steroid \\
\hline 7 & $34 / \mathrm{F}$ & Keratoconus (NMR) & None \\
\hline 8 & $42 / \mathrm{M}$ & Keratoconus (atopy) & None \\
\hline 9 & $44 / \mathrm{F}$ & Keratoconus (atopy + asthma) & Steroid \\
\hline 10 & $31 / \mathrm{M}$ & Keratoconus (atopy + eczema) & Steroid \\
\hline 11 & $18 / \mathrm{F}$ & Keratoconus; allergic conjunctivitis & Steroid \\
\hline 12 & $28 / \mathrm{F}$ & Keratoconus (atopy, eczema, corneal graft) & $\begin{array}{l}\text { None currently, } \\
\text { previously steroid }\end{array}$ \\
\hline $13 / 14$ & $19 / \mathrm{M}$ & $\begin{array}{l}\text { Keratoconus, severe vernal conjunctivitis } \\
\text { (atopy) }\end{array}$ & Steroid \\
\hline 15 & $45 / M$ & Dendritic ulcer & Steroid + aciclovir \\
\hline 16 & $64 / M$ & Dendritic ulcer & $\begin{array}{l}\text { Steroid }+ \text { aciclovir } \\
\quad(2 \text { weeks })\end{array}$ \\
\hline 17 & $35 / M$ & Dendritic ulcer & Aciclovir (1 week) \\
\hline 18 & $55 / \mathrm{F}$ & Disciform keratitis & $\begin{array}{l}\text { Steroid }+ \text { aciclovir } \\
\quad(8 \text { weeks })\end{array}$ \\
\hline 19 & $31 / \mathrm{F}$ & Microbial keratitis (hypopyon) & Antibiotics ( 2 weeks) \\
\hline 20 & $29 / \mathrm{M}$ & Microbial keratitis (mild) & None \\
\hline $21 / 22$ & $31 / \mathrm{F}$ & Rosacea keratitis & None \\
\hline 23 & $12 / \mathrm{M}$ & Thygeson's keratitis & Steroid ( 2 weeks) \\
\hline 24 & $35 / M$ & Acanthamoeba keratitis (contact lens wearer) & Antibiotics ( 3 days) \\
\hline 25 & $29 / M$ & Acanthamoeba keratitis (contact lens wearer) & Antibiotics (2 weeks) \\
\hline 26 & $37 / \mathrm{F}$ & Sjogren's syndrome $(\mathrm{Rh})$ & Unknown \\
\hline 27 & $68 / \mathrm{F}$ & Sjogren's syndrome $(\mathrm{Rh})$ & Unknown \\
\hline 28 & $55 / \mathrm{M}$ & Sjogren's syndrome $(\mathrm{Rh})$ & Unknown \\
\hline 29 & $65 / \mathrm{F}$ & Sjogren's syndrome $(\mathrm{Rh})$ & Unknown \\
\hline 30 & $13 / \mathrm{M}$ & Corneal ulcer, dry eye, cicatricial conjunctivitis & $\begin{array}{l}\text { Antibiotic }+ \text { steroid } \\
\text { ( } 2 \text { weeks })\end{array}$ \\
\hline 31 & $87 / \mathrm{M}$ & Dry eye (non-Rh) & Unknown \\
\hline 32 & $45 / \mathrm{F}$ & Dry eye (non-Rh) & Unknown \\
\hline 33 & $70 / \mathrm{F}$ & Dry eye, blepharitis (non-Rh) & Unknown \\
\hline 34 & $85 / \mathrm{F}$ & Dry eye (scleroderma) & Unknown \\
\hline
\end{tabular}

$\mathrm{Rh}=$ rheumatoid arthritis.
$20 \mu \mathrm{l}$ of a sterile solution of saline $(0.9 \% \mathrm{w} / \mathrm{v})$ was applied to the fornix of each eye.

\section{Blood samples}

Blood samples $(5 \mathrm{ml})$ were taken from healthy individuals and patients with rheumatoid arthritis and collected in blood tubes containing citrate as the anticoagulant.

\section{RELEVANT PATIENT INFORMATION}

Sixteen normal healthy volunteers aged 21-61 years who were not taking any form of medication provided the blood and/or tear samples that served as the experimental controls.

Clinical information relating to the patients with rheumatoid arthritis and those with various anterior segment diseases is given in Tables 1 and 2, respectively.

TISSUE CULTURE

To determine which MMPs were specifically produced by the conjunctiva and corneal epithelia, primary cultures of these cells were grown from the specimen tissues so that their secreted MMPs could be readily obtained from the culture media and analysed.

\section{Corneal epithelial cell cultures}

Corneal epithelial cell cultures were prepared by plating out explants taken from the anterior limbal regions of normal corneas in small petri dishes ( $5 \mathrm{~cm}$ diameter) and incubating them in RPM-I 1640 culture medium (Gibco Ltd) containing $5 \%(\mathrm{v} / \mathrm{v})$ fetal calf serum (FCS) at $36^{\circ} \mathrm{C}$ under $5 \% \quad \mathrm{CO}_{2}$. Once epithelial cell growth was established ( 7 days), the explants were removed to prevent the possibility of fibroblast proliferation. The medium was changed every 3-4 days. When near confluent, the cells were incubated for 4 days in serum-free culture medium. This was collected, centrifuged to remove any detached cells, and assayed for MMP activity.

\section{Conjunctival cell cultures}

The conjunctival biopsy tissues obtained from patients with PUK were placed in $25 \mathrm{ml}$ tissue culture flasks in a small volume of Dulbecco's MEM medium (Gibco Ltd) containing an antibiotic, antimycotic mixture (Sigma), L-glutamine, and FCS (10\% v/v). Once the tissue had adhered to the flask ( $\sim 1$ hour) more medium was added to a final volume of $3 \mathrm{ml}$. As described above, the medium was changed every 3-4 days. When the cell cultures had achieved near confluence they were incubated in serum-free medium for a period of 4 days. This was collected for MMP analysis.

PREPARATION OF LEUCOCYTES AND PLASMA FROM BLOOD SAMPLES

To investigate the possibility that the MMPs present in tears were derived from inflammatory cells, the blood samples collected were fractionated so that the MMP content of granulocytes, monocytes, and blood plasma could be assayed individually. This was achieved by placing Histopaque $1119(2.5 \mathrm{ml})$ in a $15 \mathrm{ml}$ sterile tube, sequentially overlaying 
with the same volume of Histopaque 1077 (Sigma Diagnostics) and the $5 \mathrm{ml}$ blood sample, and centrifuging at $700 \mathrm{~g}$ for 30 minutes. During this time the erythrocytes pelleted at the bottom of the tubes and the granulocytes and monocytes packed at the Histopaque $1119 / 1077$ and the Histopaque 1077/ blood plasma interfaces, respectively.

Immediately after centrifugation the blood plasma, monocytes, and granulocytes were carefully and sequentially collected using sterile pipettes. The plasma was stored at $-20^{\circ} \mathrm{C}$ until required for assaying. The monocytes and granulocytes were placed in sterile tubes containing serum-free MEM growth medium $(2 \mathrm{ml})$ and pelleted by centrifugation at $2000 \mathrm{rpm}$ for 5 minutes. After washing the cells were transferred to $25 \mathrm{ml}$ tissue culture flasks containing $2 \mathrm{ml}$ serum-free MEM medium and incubated at $36^{\circ} \mathrm{C}$ under $5 \% \mathrm{CO}_{2}$ for 7 days. The growth medium from each flask (containing ruptured cells and their liberated contents) was then removed, centrifuged at $18000 \mathrm{rpm}$ at $4^{\circ} \mathrm{C}$ to remove the cellular debris, and concentrated by centrifugation through a 10000 molecular weight cut off Amicon filter. The concentrated soluble proteins of the monocytes and granulocytes were stored at $-20^{\circ} \mathrm{C}$ prior to analysis.

DETERMINATION OF PROTEIN CONCENTRATION The protein concentration of tears and the fractionated blood samples was measured spectrophotometrically using the following methods:

(1) From the relation $\mathrm{OD}_{225} 9.18=1.0 \mathrm{mg} /$ ml. ${ }^{14}$ Reduced volume $1 \mathrm{~cm}$ path length quartz cuvettes were used and sample protein preparations were diluted with distilled water. The buffers in which the blood/tear samples were dissolved were similarly diluted to serve as blanks.

(2) From a bovine serum albumin (BSA) calibration curve. Tear samples (diluted to $150 \mu \mathrm{l})$, together with solutions of BSA of known protein concentration $(0-1 \mathrm{mg} / \mathrm{ml})$ and prepared in the same buffer used to dilute the tears, were placed in the wells of a 96 well quartz plate. Their optical densities were recorded at $280 \mathrm{~nm}$ using a Spectromax spectrophotometer (Molecular Devices). Protein concentration equivalence was determined from the constructed BSA calibration curves.

Some of the tear samples contained fluorescein and it was not therefore possible to determine their protein content by these methods.

MMP DETECTION AND ACTIVITY ASSAYS

Substrate polyacrylamide gel electrophoresis

SDS-gelatin polyacrylamide gel electrophoresis (zymography) affects in situ activation of gelatinolytic proteases and was used to separate and visualise the gelatinase activities present in tear and fractionated blood cell and plasma samples. The protocol first described by Unemori and Werb ${ }^{15}$ was followed. All samples were analysed without heating or reduction. The tear samples collected on Schirmer test strips were prepared by wetting the basal
$1 \mathrm{~cm}$ section of each strip with $5 \mu \mathrm{l}$ SDS ( $5 \%$ $\mathrm{w} / \mathrm{v}$ in $\mathrm{H}_{2} \mathrm{O}$ ), placing them in the sample wells, and filling the wells with running buffer (0.05 M Tris glycine, $\mathrm{pH} 8.8$, containing SDS $1 \% \mathrm{w} / \mathrm{v})$. These samples contained the same volume of tears but not necessarily the same protein content. Other aqueous protein samples (tears, blood plasma, monocyte and granulocyte derived) were made up to similar protein concentrations in a final volume of $25 \mu \mathrm{l}$ containing buffer $(0.05 \mathrm{M}$ TRIS $\mathrm{HCl}$, $\mathrm{pH} 7.4,10 \%$ glycerol) and $1 \%$ (w/v) SDS.

High molecular weight marker proteins (Sigma Chemical Co) were routinely included on each gel $(120 \mu \mathrm{g} / \mathrm{well})$ and electrophoresis was performed at $75 \mathrm{~V}$ for approximately 2.5 hours. The gels were then removed from their casts, washed, and incubated sequentially at $37^{\circ} \mathrm{C}$ in Triton-X100 (30 minutes) and $0.05 \mathrm{M}$ TRIS $\mathrm{HCl}, 5 \mathrm{mM} \mathrm{CaCl}{ }_{2}$ (16 hours). After staining with Coomassie blue and destaining, the resolved gelatinase activities were visualised as white bands on a blue background.

\section{Using dinitrophenyl acetate as substrate}

Since acyl transfer is a property of all proteases and proceeds in the absence of peptidase activity, the production of dinitrophenol from dinitrophenyl acetate was used to compare the total amount of protease (active and inactive) present in tear samples. ${ }^{16}$ The assays were carried out in a total volume of $200 \mu \mathrm{l}$ using 96 well plates. The reaction mixes contained $250 \mu \mathrm{M}$ dinitrophenyl acetate, tear sample of known protein content, and $0.05 \mathrm{M}$ TRIS HCl buffer, $\mathrm{pH}$ 7.4. The kinetics of dinitrophenol production were followed at $400 \mathrm{~nm}$ over a period of 20 minutes at $25^{\circ} \mathrm{C}$ using a Spectromax spectrophotometer.

Using Mca-Pro-Leu-Gly-Leu-Dpa-Ala-Arg-NH as substrate

The Gly-Leu bond of this quenched fluorescent peptide substrate ${ }^{17}$ may be cleaved by MMP-9 and MMP-2 when present in an activated form, free of their co-secreted inhibitory protein ligands known as TIMPs. To quantify the amount of activated enzyme present in tears, this substrate $(40 \mu \mathrm{M})$ was incubated with the tear samples of known protein concentration in $0.05 \mathrm{M}$ TRIS $\mathrm{HCl}$ buffer, $\mathrm{pH}$ 7.4, containing $5 \mathrm{mM} \mathrm{CaCl}$. The kinetic assays were carried out in a total volume of $150 \mu \mathrm{l}$ in black 96 well plates at $25^{\circ} \mathrm{C}$ using a Molecular Devices Spectromax Gemini fluorimeter set at excitation and emission wavelengths of $345 \mathrm{~nm}$ and $396 \mathrm{~nm}$, respectively.

ZYMOGRAPHIC SEPARATION AND QUANTIFICATION OF THE GELATINASE ACTIVITIES IN TEARS AND FRACTIONATED BLOOD PLASMA, MONOCYTES, AND GRANULOCYTES

All gels were photographed when fully destained using a polaroid camera and Kodak 665 negative film. The relative intensities/areas of the resolved gelatinase activities were subsequently determined by scanning the photograph negatives with a Biorad GS-690 imaging densitometer. 
A

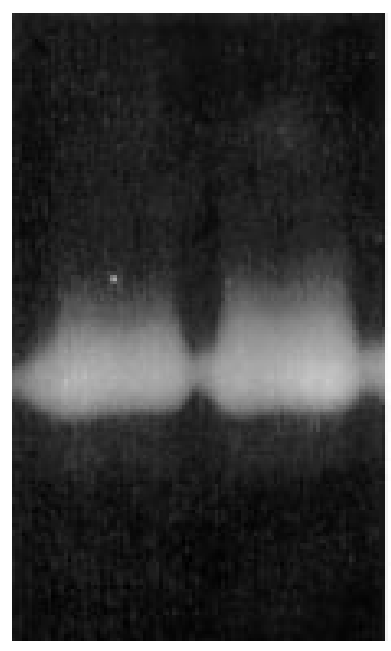

1

Figure 1 Representative zymographic gelatinase activity profiles of the MMPs secreted by primary cultures of conjunctival cells (gel A, lanes 1 and 2) and corneal epithelial cells (gel $B$, lane 1: cultured in MEM medium; lane 2: cultured in high $\mathrm{Ca}^{2+} \mathrm{MEM}$ medium which partially induces enzyme activation).

\section{STATISTICAL ANALYSIS}

Since sample numbers were relatively low, values are expressed as mean (SD). Mean values for total protease specific activity and MMP zymographic activity were compared using the Student's $t$ test for unpaired data.

\section{Results}

INVESTIGATIONS RELATING TO SOURCE OF MMP FOUND IN TEARS

Characterisation of gelatinase activities secreted by conjunctival cells and corneal epithelial cells

To ascertain which MMPs are secreted by conjunctival and corneal epithelial cells, primary near confluent cultures of these cells were incubated for 4 days in serum-free growth media. These were harvested and analysed immediately by zymography. Representative gelatinase activity profiles obtained from the media samples of conjunctival and corneal epithelial cells are shown in Figure $1 \mathrm{~A}$ and $1 \mathrm{~B}$, respectively. These data show that the major gelatinase produced by the conjunctival cells is inactive or proMMP-2 of $M_{r} 66000$. In
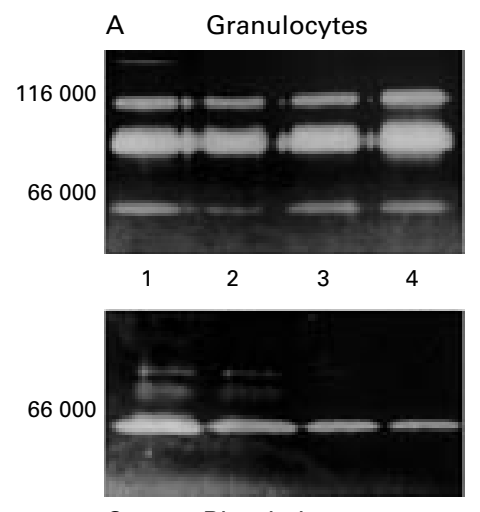

C Blood plasma

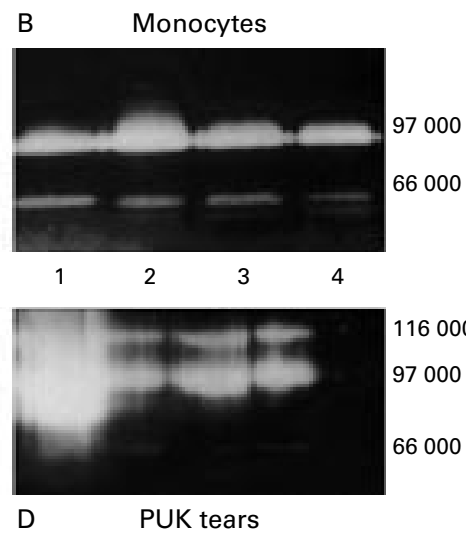

Figure 2 Representative zymographic gelatinase activity profiles of the MMPs produced by (A) granulocytes, (B) monocytes, (C) blood plasma, and (D) tears of patients with rheumatoid arthritis. addition, the corneal epithelial cells also secreted proMMP-9. Although the published molecular weight of the latter MMP is $92000,{ }^{2}$ the protein co-migrated with the protein standard of $M_{r} 97000$.

Evaluation of relation between MMPs of blood plasma and inflammatory cells and those in tear samples

In these experiments blood samples were obtained from five healthy individuals (age range 21-33 years) and from eight patients with rheumatoid arthritis with ocular complications (Table 1). Tear samples from these patients were collected on Schirmer strips. The zymographic gelatinase activities, resolved from the samples of tear, blood plasma and inflammatory cell incubation media, indicated the existence of four species of apparent $M_{r} 205000,116000$, 97000 , and 66000 . Of these, the protease associated with the band of $M_{r} 205000$ was not, apparently, an MMP since its activity was not dependent upon $\mathrm{Ca}^{2+}$, nor was it inhibited by the metal ion chelator ethylenediamine tetra-acetic acid (EDTA). The other gelatinolytic proteases have been characterised as MMPs. The activity bands corresponding to $M_{r} 66000$ and 97000 are known to be proMMP-2 and proMMP-9, respectively. The identity of the activity band of apparent $M_{r} 116000$ is unknown. Representative zymograms of the MMP activities specific to the granulocytes, monocytes, blood plasma, and tears of patients with rheumatoid arthritis with active ocular disease are shown in Figure 2. It can be seen that the tear gelatinase activity profiles, containing predominantly MMP-9 and the $M_{r} 116000$ activities, are different from those obtained for the cultured conjunctival and corneal epithelial cells. Although they also differ from those of blood plasma (which contains mainly proMMP-2) and monocytes (which produce no $M_{r} 116000$ activity but a significant amount of MMP-2), the tear gelatinase activity profiles closely resemble those obtained from ruptured granulocytes. These observations are backed by the data presented in Tables 3 and 4 which give mean densitometric estimates of the relative proportions of the three MMPs in granulocytes, monocytes, and blood plasma, and those in tears. Comparison of the ratios of the mean amounts of the MMP of $M_{r} 116000$ and MMP-9 in the tear samples of patients with rheumatoid arthritis with ocular disease with those of their granulocytes, monocytes and blood plasma gives $\mathrm{p}$ values of $>0.2,<0.005$, and $<0.001$, respectively. Similarly, comparison of the ratios of the mean amounts of MMP-2 and MMP-9 in the tear samples of these patients with those of their granulocytes, monocytes and blood plasma gives $\mathrm{p}$ values of $>0.2$, $\sim 0.005$, and $<0.001$.

INVESTIGATIONS RELATING TO THE SPECIFICITY OF TEAR FILM MMP ACCUMULATION

The tear samples used for this study were all collected using small, fine tipped pastettes and diluted to $150 \mu \mathrm{l}$ with $0.05 \mathrm{M}$ TRIS $\mathrm{HCl}, \mathrm{pH}$ $7.4,10 \%$ glycerol, before analysis. The individuals who donated these tear samples were grouped as follows: 
Table 3 Comparative estimates of the MMP content of the granulocytes, monocytes, and blood plasma of healthy subjects and patients with rheumatoid arthritis

\begin{tabular}{llll}
\hline & \multicolumn{2}{l}{ Zymographic activity/unit protein } & \\
\cline { 2 - 3 } MMP & $\begin{array}{l}\text { Rheumatoid patients } \\
(n=8)\end{array}$ & $\begin{array}{l}\text { Healthy subjects } \\
(n=5)\end{array}$ & p value \\
\hline Granulocytes & $0.74(0.22)$ & $0.92(0.40)$ & $>0.2$ \\
$M_{r}$ 116000 & $2.36(0.47)$ & $2.58(0.54)$ & $>0.2$ \\
MMP-9 & $0.04(0.05)$ & $0.30(0.16)$ & $<0.001$ \\
MMP-2 & $0.03(0.04)$ & $0.02(0.04)$ & $>0.2$ \\
Monocytes & $0.96(0.80)$ & $2.42(0.72)$ & 0.007 \\
$M_{r}$ 116 000 & $0.31(0.16)$ & $0.50(0.10)$ & 0.04 \\
MMP-9 & $0.11(0.12)$ & $0.12(0.04)$ & $>0.2$ \\
MMP-2 & $0.18(0.14)$ & $0.14(0.05)$ & 0.06 \\
Blood plasma & $0.95(0.17)$ & $0.90(0.17)$ & 0.06 \\
M 116 000 & & & \\
MMP-9 & & & \\
MMP-2 & &
\end{tabular}

Values are mean (SD).

Table 4 Comparative estimates of the MMP content of tears of healthy subjects $(C)$ and patients with rheumatoid arthritis with $(A)$ or without $(B)$ ocular complications

\begin{tabular}{lllll}
\hline \multicolumn{5}{c}{ Zymographic activity/unit tear volume } \\
\cline { 2 - 4 } Mheumatoid patients & \multicolumn{2}{l}{ Healthy subjects } & \\
\cline { 2 - 5 } & \multicolumn{2}{l}{ R $(n=10)$} & p value $(A / C ; B / C)$ \\
\cline { 2 - 5 }$M_{r} 116000$ & $0.56(0.19)$ & $0.28(0.09)$ & $0.17(0.11)$ & $<0.001 ;<0.10$ \\
MMP-9 & $2.75(1.27)$ & $1.05(0.25)$ & $0.35(0.21)$ & $<0.001 ;<0.001$ \\
MMP-2 & $0.20(0.16)$ & $0.25(0.10)$ & $0.13(0.13)$ & $>0.2 ; 0.15$
\end{tabular}

Values are mean $(\mathrm{SD})$

Table 5 Specific activities of the proteases present in tear samples from healthy individuals and patients with anterior ocular eye disease

\begin{tabular}{lll}
\hline Diagnostic group & Sample reference & $\begin{array}{l}\text { Protease specific activity } \\
(\mu m o l / m i n / m g)\end{array}$ \\
\hline Group 1 (normal) & Not given & $1.7(0.7)(\mathrm{n}=11)$ \\
Group 2a (keratoconus) & $1,2,3,6,7$ & $1.4(0.5)(\mathrm{n}=5)$ \\
Group 2b (keratoconus) & $8,9,10,12,13,14$ & $3.9(1.1)(\mathrm{n}=6)$ \\
Group 3 & 19,20 & $8.3(3.1)(\mathrm{n}=2)$ \\
$\quad$ Bacterial keratitis & 21,22 & $9.5(1.9)(\mathrm{n}=2)$ \\
Rosacea keratitis & 21 & $3.2(\mathrm{n}=1)$ \\
Thygeson's keratitis & 24,25 & $6.6(0.7)(\mathrm{n}=2)$ \\
Acanthamoeba keratitis & & $7.4(2.8)(\mathrm{n}=7)$ \\
$\quad$ Summated & 18 & $5.4(\mathrm{n}=1)$ \\
Group 4 (herpes) & 30 & $6.0(\mathrm{n}=1)$ \\
Group 5 (dry eye) & &
\end{tabular}

Table 6 Comparative estimates of the MMP content of the tears of healthy individuals and patients with ocular disease

\begin{tabular}{llll}
\hline & & \multicolumn{2}{l}{$M M P$ zymographic activity/unit protein } \\
\cline { 3 - 4 } Diagnostic group & No of sample & $M_{r} 116000$ & $M M P-9$ \\
\hline Group 1 (normal) & 10 & $0.07(0.09)$ & $0.14(0.19)$ \\
$\quad$ Normal? & 1 & 0.05 & 0.90 \\
Group 2a (keratoconus) (1-8) & 7 & $0.27(0.32)$ & $0.51(0.30)$ \\
Group 2b (keratoconus) (9-15) & 7 & $1.70(0.96)$ & $4.32(1.90)$ \\
Group 3 & & & \\
$\quad$ Microbial keratitis & 2 & $0.15(0.07)$ & $0.25(0.21)$ \\
$\quad$ Rosacea keratitis & 2 & 0.10 & 0.40 \\
$\quad$ Thygeson's keratitis & 1 & $1.70(0.5)$ & $2.55(1.9)$ \\
$\quad$ Acanthamoeba & 2 & $1.70(1.13)$ & $4.57(2.2)$ \\
Group 4 (herpes) & 4 & & \\
$\quad$ & & $0.62(0.46)$ & $3.68(1.46)$ \\
Group 5 & 4 & $0.99(0.48)$ & $3.74(0.78)$ \\
$\quad$ Sjogren's syndrome & 5 & & \\
$\quad$ Dry eye (non-Rh) & & & \\
\hline
\end{tabular}

$\mathrm{ND}=$ not detected $\mathrm{Rh}=$ rheumatoid arthritis

Group 1: healthy individuals $(\mathrm{n}=11$; age 25-61 years).

Group 2a: patients with keratoconus but no recorded history of atopic disease.

Group 2b: patients with keratoconus and associated atopic disease.
Group 3: patients with non-herpetic corneal keratitis.

Group 4: patients with herpetic eye disease.

Group 5: patients with dry eye (with or without systemic autoimmune disease).

\section{Proteolytic enzyme content of the collected tear} samples

The specific activities of all proteolytic enzymes present in the tear samples were calculated from the rate of hydrolysis of nitrophenylacetate and expressed as $\mathrm{nmol} / \mathrm{min} / \mathrm{mg}$ protein. The data obtained are given in Table 5 but could not be calculated for most of the patients in groups 4 and 5 because their tear samples contained fluorescein. Nevertheless, they show that the mean specific activities of the proteases present in the tears of patients in groups $2 b, 3,4$, and 5 were higher than those of normal healthy individuals included in group 1 ( $p$ values of $<0.001$ were obtained for patients in groups $2 \mathrm{~b}$ and 3 compared with normal individuals). The only patients whose tear protease content was comparatively low and similar to that of healthy individuals were those with keratoconus without atopic disease (group 2a).

\section{Quantitative analysis of MMPs present in} collected tear samples

The MMPs present in the tear samples, including those that contained fluorescein, were separated and visualised by zymography. Those of known protein concentration were applied to the gels at similar protein concentration. Tear samples containing fluorescein were applied to the gels in the median loading volume of the samples of known protein concentration. After electrophoresis, development of the gels, and obtaining their photographic negatives, the relative concentrations of the resolved MMP activities were measured by densitometry. These data are shown in Table 6.

The tear samples that contained appreciable quantities of the MMP of $M_{r} 116000$ and MMP-9 were from patients in groups $2 b$ (keratoconus with atopic disease), 4 (herpetic eye disease), and 5 (dry eye with or without systemic autoimmune disease). With one exception, little or no zymographic MMP activity was detected in the tear samples of the normal subjects. The tear samples of patients in group 2a (keratoconus with no atopic disease) contained small amounts of the MMP of $M_{r} 116000$ and MMP-9 and the mean values obtained were slightly higher than those calculated for the tear samples of healthy subjects $(p=0.06$ and 0.02 , respectively). The other tear samples that contained low levels of these MMPs were, with the exception of the patients with acanthamoeba keratitis, from those in group 3 (patients with non-herpetic corneal keratitis). Since relatively high levels of general proteolytic activity were detected in the latter tear samples, they may have contained proteases other than MMPs. On the other hand, the measured protein content of these samples was, for unknown reasons, only one 
Table 7 Specific activities of tear sample MMPs assayed against Mca-septapeptide

\begin{tabular}{lll}
\hline Ocular condition & Sample reference & $\begin{array}{l}\text { Specific activity } \\
\text { (fluorescence } \\
\text { units/min/mg) }\end{array}$ \\
\hline Group 1 $(\mathrm{n}=4)$ & Not given & 0 \\
Group 2a & $1,2,4,7$ & 0 \\
Group 2b & 11,14 & 0 \\
Group 3 & $8,12,13$ & $18(3)$ \\
Group 4 & $20,21,22$ & 0 \\
Group 5 & 18 & 24 \\
Commercial preparation & 30 & 13 \\
\hline
\end{tabular}

third of that found in the tears of normal healthy subjects (data not shown).

Peptidase activities of the MMPs present in the collected tear samples

To determine whether activated MMP was present in the tears of patients with anterior segment disease, a selection of the tear samples collected was assayed against the MMP-9/ MMP-2 susceptible quenched fluorescent peptide. The results obtained are shown in Table 7. Of the tear samples assayed, only those that exhibited the highest overall protease and zymographic MMP activities contained activated enzyme and were from patients with keratoconus with atopic disease (group 2b) and from individuals with herpetic eye disease and cicatricial conjunctivitis. However, although activated MMPs were detected in these tear samples, their specific activities were extremely low compared with that of a commercially obtained preparation of activated MMP-2.

\section{Discussion}

Non-infectious ocular conditions that cause corneal thinning include those associated with rheumatoid arthritis or other systemic autoimmune diseases and result in corneal perforation (such as PUK) and those that progress independently of the immune system and do not result in perforation (such as keratoconus). Given this, it is apparent that inflammatory cells play an essential part in corneal perforation. It is also apparent that perforation requires the presence of an enzyme that can hydrolyse type I collagen, the main structural component of the corneal stroma. To date, the only known mammalian enzymes that are capable of achieving this are neutrophil collagenase (MMP-8, produced by neutrophils) and interstitial collagenase (MMP-1, produced by macrophages and fibroblasts). ${ }^{2}$ Which of these collagenases may be involved in the destruction of the cornea remains unknown. There is reliable evidence that macrophages penetrate the corneas of patients with PUK and, although MMP-1 has been immunologically detected in these corneas, ${ }^{9}$ it has also been reported that this is an endogenous enzyme synthesised by keratocytes. ${ }^{18}{ }^{19}$ Although our own data do not support the latter of these possibilities, we have observed upregulation of MMP-2 production in keratocytes derived from PUK corneas and an accumulation of MMP (mainly MMP-9) in the tears of patients with active disease. ${ }^{13}$ The present investigation was initiated to establish the source of the tear film MMPs and to determine whether they may be directly involved in PUK and other ocular disease processes.

To investigate the source of the tear film MMPs in patients with rheumatoid arthritis with ocular complications, the zymographic activity profiles of the MMPs present in their tears were compared with those of the MMPs secreted by conjunctival and corneal epithelial cells and those of the MMPs obtained from fractionated blood plasma and leucocytes (granulocytes and monocytes). The tear samples were collected on Schirmer test strips and their zymographic activity profiles contained an MMP of $M_{r} 116000$, MMP-9 and, in low abundance, MMP-2. The zymographic activity profiles of the MMPs found in blood plasma and in the culture media of conjunctival and corneal epithelial cells precluded the possibility that these tissues were the source of the tear film MMPs. The lack of the $M_{r} 116000$ activity in the zymographic activity profile of the MMPs obtained from monocytes also indicated that these inflammatory cells contributed little to the complement of MMPs found in tears. Interestingly, however, it was noted that the specific activities of MMP-9 and MMP-2 recovered from monocytes of rheumatoid patients were significantly less than those of the enzymes recovered from monocytes of healthy subjects. Such differences were not observed when the specific activities of the individual MMPs recovered from granulocytes of normal subjects and patients with rheumatoid arthritis were compared, but the MMP profiles of these blood cells were virtually identical to those of tear film MMPs. It was therefore concluded that the granulocytes are the main source of MMPs found in tears of patients with rheumatoid arthritis. There exists the possibility that these enzymes are contained within granulocytes in tears. It is considered more likely that they are free in solution in the tear film and derived from granulocytes attracted to sites of inflammation either by external agents or by autoimmune disease.

Analysis of tear samples of patients with a variety of anterior segment diseases other than PUK indicated that the phenomenon of MMP accumulation was not unique to this disease. Initial experiments, in which the overall protease activity of the tear samples that did not contain fluorescein was measured, indicated that they divided into two groups of either low or high specific activity. The tear samples of low protease specific activity were obtained from normal healthy individuals (group 1) and patients with keratoconus without atopic disease (group 2a). With the exception of a tear sample from one of the normal participants, these tear samples also contained little zymographic MMP activity. Conversely, with the exception of most of the tear samples of patients in group 3, those of high protease specific activity also contained appreciable quantities of proMMP-9 and the species of $M_{r}$ 116000 . These tear samples were collected from patients with keratoconus with atopic disease (group 2b), those with herpetic eye 
disease (group 4), dry eye (group 5), and the patients with acanthamoeba keratitis included in group 3.

Previous work in which the tears of patients with PUK were assayed zymographically using a variety of collagenous substrates provided no evidence for the existence of activated MMP. ${ }^{13}$ To ascertain whether any of the tear samples collected for this investigation contained activated enzyme, some were assayed against an MMP-9/MMP-2 susceptible quenched fluorescent peptide substrate. Of these tear samples, the few that exhibited activity, albeit low, included those of the patients with keratoconus who had the highest zymographic MMP activities and patients with herpetic eye disease (disciform keratitis) and cicatricial conjunctivitis. In considering the mechanisms by which MMP activation could have occurred, we have found that the serine protease elastases from Acanthamoeba sp and neutrophils are capable of activating corneal keratocyte secreted MMP-2 (unpublished data). Other authors have also found that similar bacterial enzymes (such as Pseudomonas elastase) may cleave the autoinhibitory $\mathrm{N}$-terminal peptide from proM$\mathrm{MPs}^{20} 21$ and implicated polymorphonuclear (PMN) leucocytes in MMP processing. Apparently, $\mathrm{O}^{\circ}$ and $\mathrm{NO}^{\circ}$ may be generated by activated macrophages and PMNs as a result of immunological responses to proinflammatory cytokines, and these free radicals may attack the cysteine bonded active site zinc ion. ${ }^{21}$ In addition to activating MMPs, free radical nitration and oxidative reactions presumably could also affect inactivation of the MMP inhibitors known as TIMPs and the breaching of epithelial cell barriers if these cells were the target of inflammatory cell attack in systemic disease. There is some evidence that surface proteins of epithelial cells are targeted by circulating antibodies in patients with rheumatoid arthritis. ${ }^{22}{ }^{23}$ If this were the case, once their basement membranes had been accessed and disrupted by the action of the inflammatory cell gelatinolytic MMPs or autoactivated endogenous MMP-9/MMP-2, macrophages would be free to invade the corneal stroma and there liberate their matrix degrading enzymes, particularly MMP-1. This hypothetical mechanism of PUK progression would partly explain why the corneas of patients with keratoconus and, for example, severe vernal or allergic conjunctivitis may be surrounded by inflammatory cells and an activated gelatinolytic MMP, but are not invaded by these cells and do not perforate.

In conclusion, it has been shown that the tears of patients with anterior segment diseases induced by systemic disease or those that induce an inflammatory response contain MMP-9 and an MMP of $M_{r} 116000$. The main source of these enzymes appears to be the granulocyte fraction of white blood cells that accumulate at sites of ocular inflammation. In some cases a small proportion of the detected enzyme existed in an activated form. While this MMP may contribute to the breakdown of tear film proteoglycan, it is considered likely that its overall contribution to ocular disease processes is minimal. The inflammatory cell MMPs that cause major ocular tissue disruption and can activate endogenous MMPs are probably those that are produced and remain within the tissue that the inflammatory cells have invaded.

The authors are very grateful to the National Eye Research Centre (NERC) for financial support.

1 Murphy GJP, Murphy G, Reynolds JJ. The origin of matrix metalloproteinases and their familial relationships. FEBS Lett 1991;289:4-7.

2 Matrisan LM. The matrix degrading metalloproteinases. Bioessays 1992;14:455-63.

3 Sakamoto S, Sakamoto M. Degradative processes of connective tissue proteins with special emphasis on collagenolysis and bone reabsorption. Mol Aspects Med 1988;10:301-428

4 Woessner JF. Metalloproteinase and their inhibitors in connective tissue remodelling. FASEB f 1991;5:2145-54.

5 Matrisan LM. Metalloproteinases and their inhibitors in matrix remodelling. Trends Genet 1990;6:121-5.

6 Matrisan LM, Bowden GT, Krieg P, et al. The mRNA coding for the secreted transin is expressed more abundantly in malignant than in benign tumours. Proc Natl Acad Sci USA 1986;83:9413-7.

7 Dean DD, Martel-Pelletier J, Pelletier JL, et al. Evidence for metalloproteinase inhibitor imbalance in human osteoarthritic cartilage. F Clin Invest 1989;84:678-85.

8 Liotta LA, Steeg PS, Stetler-Stevenson WG. Cancer metastasis and angiogenesis: an imbalance of positive and negative regulation. Cell 1991;64:327-36.

9 Riley, GP, Harrall RL, Watson PG, et al. Collagenase (MMP-1) and TIMP in destructive corneal disease associated with rheumatoid arthritis. Eye 1995;9:703-18.

10 Gross J. An essay on biological degradation of collagen. In: Hay ED, ed. Cell biology of the extracellular matrix. New York: Plenum Press 1982:217-58.

11 Collier JE, Wilhelm SM, Eizen AZ, et al. H-ras oncogenetransformed human bronchial epithelial cells (TBE-1) ment membrane collagen. F Biol Chem 1988;263:6579-87.

12 Murphy G, Ward R, Hembry RM, et al. Characterisation of gelatinase from pig polymorphonuclear leucocytes. Biochem $71989 ; 258: 463-72$.

13 Smith VA, Hoh HB, Easty DL. Role of ocular matrix metalloproteinases in peripheral ulcerative keratitis. $\mathrm{Br} f$ loproteinases in peripheral
Ophthalmol 1999;83:1376-83.

14 Hall BG, Hartl DL. Regulation of newly synthesised enzymes. II. The ebg repressor. Genetics 1975;81:427-35.

15 Unemori EN, Werb Z. Reorganisation of polymerised actin: a possible trigger for induction of procollagenase in 1986;103:1021-31.

16 Smith VA, Hoh HB, Littleton M, et al. Over-expression of a gelatinase A activity in keratoconus. Eye 1995;9:429-33.

17 Knight CG, Willenbrock F, Murphy G. A novel coumarinlabelled peptide for sensitive continuous assays of the labelled peptide for sensitive continuous assays of
matrix metalloproteinases. FEBS Lett 1992;296:263-6.

18 Berman M, Leary R, Gage J. Collagenase from corneal cell cultures and its modulation by phagocytosis. Invest cultures and its modulation by
Ophthalmol Vis Sci 1979;18:588-601.

19 Berman MB. Regulation of corneal fibroblast MMP-1 secretion by cytochalasins. Cornea 1994;13:51-7.

20 Matsumoto K, Shams NBK, Hanninen LA, et al. Proteolytic activation of corneal matrix metalloproteinase by Pseudomonas aeruginosa elastase. Curr Eye Res 1992;11:1105-9.

21 Maeda H, Okamoto T, Akaike T. Human matrix metalloprotease activation by insults of bacterial infection involving proteases and free radicals. Biol Chem 1998;379: 193-200.

22 John SL, Morgan K, Tullo AB, et al. Corneal autoimmunity in patients with peripheral ulcerative keratitis (PUK) in association with rheumatoid arthritis and Wegener's granulomatosis. Eye 1992;6:630-6.

23 Reynolds I, John SL, Tullo AB, et al. Characterisation of two corneal epithelium derived antigens associated with vasculitis. Invest Ophthalmol Vis Sci 1998;39:2594-601. 